\title{
Uncrewed Ocean Gliders and Saildrones Support Hurricane Forecasting and Research
}

\begin{abstract}
By Travis N. Miles, Dongxiao Zhang, Gregory R. Foltz, Jun A. Zhang, Christian Meinig, Francis Bringas, Joaquin Triñanes, Matthieu Le Hénaff, Maria F. Aristizabal Vargas, Sam Coakley, Catherine R. Edwards, Donglai Gong, Robert E. Todd, Matthew J. Oliver, W. Douglas Wilson, Kerri Whilden, Barbara Kirkpatrick, Patricia Chardon-Maldonado, Julio M. Morell, Debra Hernandez, Gerhard Kuska, Cheyenne D. Stienbarger, Kathleen Bailey, Chidong Zhang, Scott M. Glenn, and Gustavo J. Goni
\end{abstract}

\section{INTRODUCTION}

In the United States alone, hurricanes have been responsible for thousands of deaths and over US\$1 trillion in damages since 1980 (https://www.ncdc.noaa.gov/billions/). These impacts are significantly greater globally, particularly in regions with limited hurricane early warning systems and where large portions of the population live at or near sea level. The high socioeconomic impacts of tropical cyclones will increase with a changing climate, rising sea level, and increasing coastal populations. To mitigate these impacts, efforts are underway to improve hurricane track and intensity forecasts, which drive storm surge models and evacuation orders and guide coastal preparations. Hurricane track forecasts have improved steadily over past decades, while intensity forecasts have lagged until recently (Cangialosi et al., 2020). Hurricane intensity changes are influenced by a combination of large-scale atmospheric circulation, internal storm dynamics, and air-sea interactions (Wadler et al., 2021, and references therein).

Components of the sustained ocean observing system (e.g., profiling floats, expendable bathythermographs, drifters, moorings) are useful for understanding the role of the ocean in hurricane intensity changes. However, gaps in the ocean observing system, particularly collection of data near the air-sea interface and in coastal regions, boundary currents (e.g., the Gulf Stream, Kuroshio, among others), and areas with complex currents and seafloor topography (e.g., the Caribbean Sea), have led to difficulties in accurately representing upper ocean features and processes in numerical ocean models. Employment of uncrewed ocean observing platforms has begun to fill these gaps by offering rapid relocation and adaptive sampling of regions and ocean features of interest. These platforms include autonomous underwater gliders (Figure 1; Testor et al., 2019) and surface vehicles (Meinig et al., 2019). Uncrewed surface vehicles (USVs), such as saildrones and wave gliders, are systems designed for data collection in hazardous conditions. Data collected by these platforms have improved our understanding of upper ocean temperature and salinity stratification and mixing processes and are becoming critical in improving operational ocean and coupled air-sea hurricane forecast models (Domingues et al., 2021).

This paper provides a broad overview of the ongoing US hurricane glider project and details of a new effort with the Saildrone USV during the 2021 hurricane season. While this article focuses on the US East Coast, Gulf of Mexico, and Caribbean Sea, similar efforts are underway in Korea, the Philippines, Japan, and China, among other countries.

\section{THE OCEAN AND HURRICANES}

The ocean influences hurricane development through the transfer of heat and momentum across the air-sea interface (Le Hénaff et al., 2021; Wadler et al., 2021, and references therein). Warm sea surface temperatures are conducive to hurricane intensification while cool temperatures often lead to weakening. Research shows that upper ocean temperature and salinity ahead of and during hurricanes can evolve rapidly (Glenn et al., 2016). The evolution of the upper ocean depends on various factors, including wind speed and direction, wave state, upper ocean stratification, and interactions with the coastal ocean, among others. To accurately forecast hurricane intensity in the western Atlantic, coupled ocean and atmosphere operational forecast models must resolve large-scale warm ocean currents (e.g., the Gulf Stream, the Gulf of Mexico Loop Current, and their associated meanders and eddies; Todd et al., 2018); freshwater layers from large rivers such as the Amazon-Orinoco and Mississippi (Domingues et al., 2021), which can inhibit ocean mixing and maintain warm upper ocean temperatures ahead of storms; and shallow
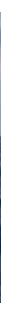

FIGURE 1. Underwater gliders: (a) Slocum. (b) Spray. (c) SeaExplorer. (d) Seaglider. For more information on gliders, go to https://ioos. noaa.gov/project/underwater-gliders/. Photo credits: (a) Matt Souza, University of Virgin Islands (b) Robert E. Todd, WHOI (c) ALSEAMAR (d) NOAA AOML 
continental shelf features like the Mid-Atlantic Cold Pool, a cold bottom water mass that can rapidly mix to the surface and weaken storms before landfall (Glenn et al., 2016). New technologies such as uncrewed ocean gliders and surface vehicles, alongside more established components of the Global Ocean Observing System (e.g., Argo floats, air-launched expendable bathythermographs, and satellite sensors), will improve existing hurricane forecast and warning systems and support critical research to develop the next generation systems.

\section{UNDERWATER GLIDERS}

Gliders (Figure 1) have emerged as a major component of US and international multi-hazard warning systems. Since 2014, the operation of gliders for hurricane research and forecasts has been a joint effort by the US National Oceanic and Atmospheric Administration (NOAA), the US Integrated Ocean Observing System (IOOS) Regional Associations, academic institutions, the US Navy, the National Science Foundation, private companies, and other regional and international partners. Gliders are unique in their maneuverability, able to profile through the water column as deep as 1,000 $\mathrm{m}$ with vertical and horizontal speeds of $\sim 10-20 \mathrm{~cm} / \mathrm{s}$ and $\sim 25 \mathrm{~cm} / \mathrm{s}$, respectively. Standard glider sensor packages include temperature, salinity, and density, while some gliders also collect profiles of water speed and direction. Biogeochemical measurements can include oxygen, phytoplankton, and particle concentration for water quality assessment. Numerous advanced sensor packages continue to be developed and integrated. Gliders can collect data as frequently as every two seconds, providing submeter-scale measurements in the vertical, though lower sample rates are typically used to conserve power and minimize surface time.

While opportunistic glider deployments were carried out for hurricane research in the first decade of this century, coordinated regional fleets were first used for hurricane research and operational model development in 2014. These experiments were supported by the congressionally authorized Disaster Recovery Act following the devastation of Superstorm Sandy in October 2012. Studies from this time period (Glenn et al., 2016; Domingues et al., 2021, and references therein) demonstrated the unique capabilities of gliders to contribute to our understanding of ocean feedbacks on hurricane intensity and to the improved accuracy of coupled hurricane model forecasts.

Following the coastal impacts of Hurricanes Irma and Maria in 2017, large multi-institution fleets of gliders have now been deployed to collect data. These efforts, and other leveraged glider observations, have resulted in over 280 deployments, collecting nearly 600,000 ocean profiles during 13,000 glider days in hurricane seasons from 2018 to 2021 in the open Atlantic Ocean, the Caribbean Sea, the Gulf of Mexico, and off the US East Coast (Figure 2).

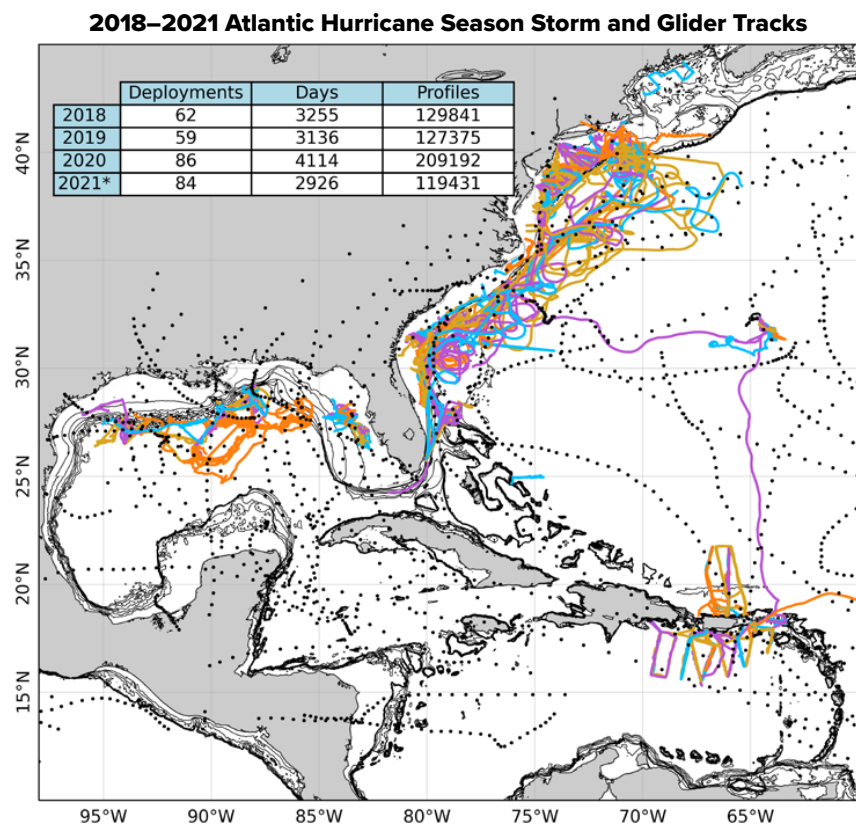

FIGURE 2. Glider tracks from the 2018 (orange), 2019 (purple), 2020 (yellow), and 2021* (blue) hurricane seasons (May to November) generated with data from the Integrated Ocean Observing System Glider Data Assembly Center (https://gliders.ioos.us), with an overlay of tropical cyclone tracks (black dots) from the International Best Track Archive for Climate Stewardship (IBTrACS, https://www.ncdc.noaa.gov/ ibtracs/). The table in the upper left indicates the yearly breakdown of glider deployments, glider days at sea, and collected profiles. (*2021 data were extracted on 09/17/2021 prior to the completion of the Atlantic hurricane season.)

These gliders were strategically deployed in regions with high probabilities of hurricane passage, near ocean features that impact hurricane intensity, and near vulnerable coastal population centers.

Gliders have collected data in the ocean under more than 30 Atlantic tropical cyclones. These data are provided to the publicly accessible IOOS Glider Data Assembly Center (DAC; https://gliders.ioos.us), where they are accessed in real time and distributed through the World Meteorological Organization Global Telecommunication System (GTS). This distribution pathway allows NOAA to access the glider profiles for assimilation into the operational numerical models, such as the global Real Time Ocean Forecast System, used to initialize the ocean component of coupled hurricane forecast models such as the NOAA Hurricane Weather Research and Forecasting model.

A data impact study of Hurricane Maria (2017) showed that, out of the suite of in situ ocean observing platforms, glider data locally generate the largest error reduction in intensity forecasts within NOAA operational forecast models (Domingues et al., 2021). Additional model improvements were achieved when glider data were used alongside other ocean observations (Halliwell et al., 2020). Gliders have also contributed to new understanding of hurricane-forced coastal ocean circulation (Glenn et al., 2016), impacts on boundary currents (Todd et al., 2018), ahead-of-eye mixing processes (Glenn et al., 2016), and 
impacts of these processes on hurricane intensity. With the development of new sensors and public data repositories, gliders additionally contribute to the understanding of regional ecosystems, fisheries, water quality, harmful algal blooms, ocean warming and climate change, and renewable energy, among other coastal processes, stressors, and solutions.

\section{A NEW UNCREWED SURFACE VEHICLE FOR HURRICANE OPERATIONS AND RESEARCH}

To continue making significant progress toward understanding and predicting hurricane intensity changes, new technologies are being tested to provide improved estimates of air-sea fluxes in a hurricane environment. Efforts by public-private partnerships have rapidly advanced development of USVs into air-sea interaction observing platforms (Meinig et al., 2019). The use of renewable wind, surface wave, and solar energy for propulsion and instrumentation has increased USV endurance up to 12 months and enabled installation of more sensors (Zhang et al., 2019). Specifically, Saildrone USVs (Figure 3) are equipped with 15 sensor packages that measure 22 essential ocean and climate variables, such as sea surface temperature, salinity, oxygen, wave height and period, near-surface winds, air temperature, relative humidity, solar and longwave radiation, and barometric pressure (Zhang et al., 2019).

During the 2021 hurricane season, NOAA supported for the first time deployment and operation of five specially designed Saildrone USVs to measure air-sea interaction in regions where Atlantic tropical cyclones occur frequently. Compared to conventional Saildrone platforms, these extreme weather systems have shorter wings for increased stability, allowing them to operate in hurricane-force winds and in the presence of large breaking waves (Figure 3). For the 2021 mission, the five extreme weather Saildrone USVs were strategically located in regions of the western tropical Atlantic, the Caribbean, and near the US East Coast to maximize the probability of encountering at least one hurricane or tropical storm. The USVs continuously measured properties in the near-surface atmosphere and ocean and transmitted one-minute averaged data to the GTS and data centers in real time for assimilation into forecast models and for other public use.

The extreme weather Saildrone USVs travel at speeds of about 30-150 km per day, depending on winds and currents, and can be directed to locations directly in tropical cyclone paths. For example, during the 2021 mission, Saildrone SD-1031 traveled $35 \mathrm{~km}$ to the east during the 24 hours before the arrival of Hurricane Henri, bringing it within $50 \mathrm{~km}$ of the eye of the storm. The ability to move the USV into storm paths increases the chances of acquiring ocean-atmosphere measurements in high-wind conditions. These measurements are extremely valuable because the rates of heat and momentum exchange between the ocean and tropical cyclones, and storm dependence on the states of the ocean and atmosphere, are not well known, in part because there are so few measurements. The highlight of the mission was the passage of Category 4 Hurricane Sam directly over Saildrone SD-1045 on September 30 (Figure 4), when winds up to $56 \mathrm{~m} / \mathrm{s}$ (at a height of $5 \mathrm{~m}$ ) and waves as high as $14 \mathrm{~m}$ were recorded in the hurricane's northern eyewall. Saildrone SD-1045 then traveled across the eastern edge of the eye and through the southern eyewall, recording the first-ever video from the sea surface of the eyewall of a major hurricane (https://www.saildrone. $\mathrm{com} /$ press-release/ocean-drone-captures-video-insidecategory-4-hurricane).

During the August-October 2021 Atlantic hurricane mission, two other tropical storms passed close to saildrones: Grace passed directly over Saildrone SD-1048 south of Puerto Rico, and Fred passed about $140 \mathrm{~km}$ to the north of the same saildrone. When they were not being directed toward tropical cyclones, the mission scientists worked with Saildrone Inc. pilots to keep four of the Saildrone USVs close to gliders to obtain nearly collocated measurements of the upper ocean and nearsurface atmosphere (Figure 4). In addition, NOAA's hurricane reconnaissance aircraft acquired collocated profiles of atmospheric 
temperature, humidity, and winds from dropsondes together with ocean temperature profiles collected from air-launched expendable bathythermographs in Hurricane Henri. NASA aircraft also launched dropsondes near some of the Saildrone USVs during its Convective Processes Experiment - Aerosols \& Winds (CPEX-AW) field campaign. These unique data sets will be valuable for advancing knowledge of interactions between the subsurface ocean and tropical cyclones.

\section{CONCLUSIONS}

Both autonomous underwater gliders and uncrewed surface vehicles such as saildrones represent advanced ocean observing technologies that are revolutionizing both our understanding of and ability to forecast hurricane track and intensity. To realize their full potential, these technologies will continue to be more closely integrated with established regional and global ocean and atmosphere observing platforms. One of the main objectives of these projects during the 2021 Atlantic hurricane season was to obtain collocated and simultaneous measurements of the upper ocean and air-sea coupling within a hurricane. These combined observations will provide new insights into the coevolution and coupling of the ocean and atmosphere to better predict storm intensity. Future hurricane observations should encourage more closely coordinated deployments of underwater, near-surface, and airborne observations in order to better understand rapid hurricane intensity changes. As ocean, atmosphere, and coupled model architecture and data assimilation capabilities continue to coevolve and improve, these observing systems and their shoreside cyberinfrastructure will become critical components of operational forecasting systems in the United States.

\section{REFERENCES}

Cangialosi, J.P., E. Blake, M. Demaria, A. Penny, A. Latto, E. Rappaport, and V. Tallapragada. 2020. Recent progress in tropical cyclone intensity forecasting at the national hurricane center. Weather and Forecasting 35(5):1,913-1,922, https://doi.org/10.1175/ WAF-D-20-0059.1.

Domingues, R., M. Le Hénaff, G.R. Halliwell, J.A. Zhang, F. Bringas, P. Chardon-Maldonado, H. Kim, J.M. Morell, and G.J. Goni. 2021. Ocean conditions and the intensification of three major Atlantic hurricanes in 2017. Monthly Weather Review 149(5):1,265-1,286, https://doi.org/ 10.1175/MWR-D-20-0100.1.

Glenn, S.M., T.N. Miles, G.N. Seroka, Y. Xu, R.K. Forney, F. Yu, H. Roarty, O. Schofield, and J. Kohut. 2016. Stratified coastal ocean interactions with tropical cyclones. Nature Communications 7:10887, https://doi.org/ 10.1038/ncomms10887.

Halliwell, G.R., G.J. Goni, M.F. Mehari, V.H. Kourafalou, M. Baringer, and R. Atlas. 2020. OSSE assessment of underwater glider arrays to improve ocean model initialization for tropical cyclone prediction. Journal of Atmospheric and Oceanic Technology 37(3):467-487, https://doi.org/10.1175/JTECH-D-18-0195.1.

Le Hénaff, M., R. Domingues, G. Halliwell, J.A. Zhang, H.S. Kim, M. Aristizabal, T. Miles, S. Glenn, and G. Goni. 2021. The role of the Gulf of Mexico ocean conditions in the intensification of Hurricane Michael (2018). Journal of Geophysical Research: Oceans 126(5):e2020JC016969, https://doi.org/10.1029/2020JC016969.

Meinig, C., E.F. Burger, N. Cohen, E.D. Cokelet, M.F. Cronin, J.N. Cross, S. de Halleux, R. Jenkins, A.T. Jessup, C.W. Mordy, and others. 2019.

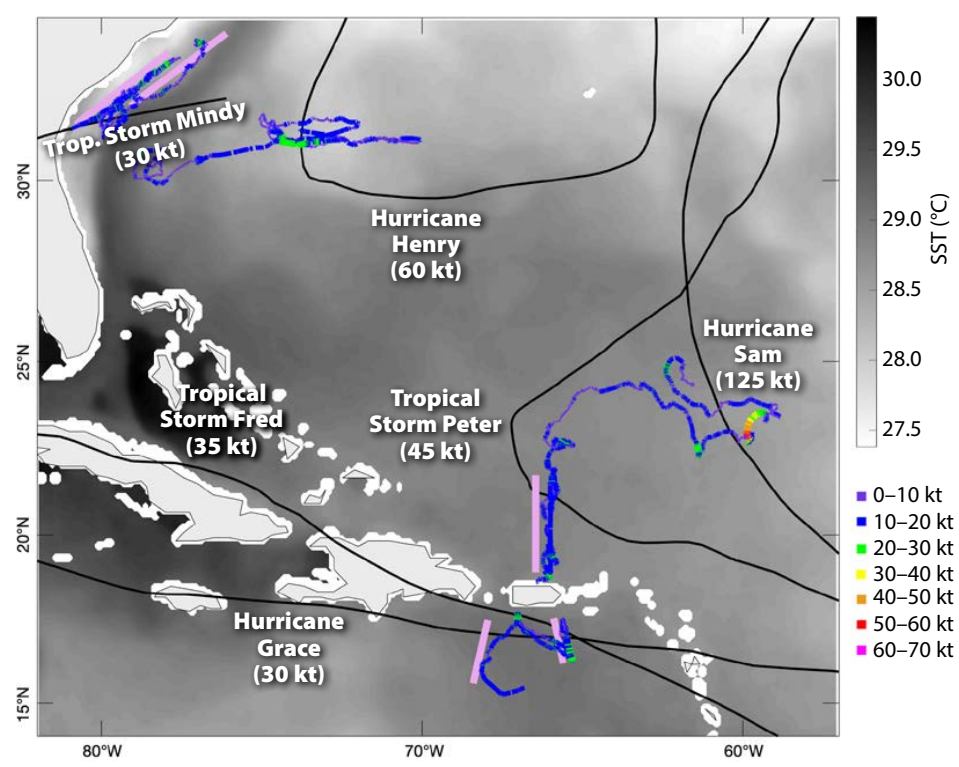

FIGURE 4. Colored Saildrone tracks during August to October 2021 represent one-hour averaged wind speed measured at a height of $5 \mathrm{~m}$. Saildrone data from the mission are available at https://www.pmel.noaa.gov/saildronehurricane2021\%. Black lines show tracks of tropical cyclones that passed close to one or more Saildrones. Storm names and their maximum sustained one-minute wind speeds at locations of closest approach to a Saildrone are also indicated. Thicker pink lines indicate repeat tracks of ocean gliders that obtained collocated measurements with Saildrones. Background shading is sea surface temperature averaged during August to September 2021.

Public-private partnerships to advance regional ocean observing capabilities: A Saildrone and NOAA-PMEL case study and future considerations to expand to global scale observing. Frontiers in Marine Science 6:448, https://doi.org/10.3389/fmars.2019.00448.

Testor, P., B. de Young, D.L. Rudnick, S. Glenn, D. Hayes, C.M. Lee, C. Pattiaratchi, K. Hill, E. Heslop, V. Turpin, and others. 2019. OceanGliders: A component of the integrated GOOS. Frontiers in Marine Science 6:422, https://doi.org/10.3389/fmars.2019.00422.

Todd, R.E., T.G. Asher, J. Heiderich, J.M. Bane, and R.A. Luettich. 2018. Transient response of the Gulf Stream to multiple hurricanes in 2017. Geophysical Research Letters 45(19):10,509-10,519, https://doi.org/ 10.1029/2018GL079180.

Wadler, J.B., J.A. Zhang, R.F. Rogers, B. Jaimes, and L.K. Shay. 2021. The rapid intensification of Hurricane Michael (2018): Storm structure and the relationship to environmental and air-sea interactions. Monthly Weather Review 149(1):245-267, https://doi.org/10.1175/ MWR-D-20-0145.1.

Zhang, D., M.F. Cronin, C. Meinig, J.T. Farrar, R. Jenkins, D. Peacock, J. Keene, A. Sutton, and Q. Yang. 2019. Comparing air-sea flux measurements from a new unmanned surface vehicle and proven platforms during the SPURS-2 field campaign. Oceanography 32(2):122-133, https://doi.org/10.5670/oceanog.2019.220.

\section{ACKNOWLEDGMENTS}

The Saildrone project work was supported by NOAA's Office of Marine and Aviation Operations (OMAO) and Office of Oceanic and Atmospheric Research (OAR): Weather Program Office (NA21OAR4590394), Atlantic Oceanographic and Meteorological Laboratory (AOML), Pacific Marine Environmental Laboratory (PMEL), Cooperative Institute for Climate, Ocean and Ecosystem Studies (CICOES/UW), and the Oceans Portfolio. The glider work was supported by NOAA (Integrated Ocean Observing System, Global Ocean Monitoring and Observing Program, IOOS Regional Associations-MARACOOS, CARICOOS, SECOORA, and GCOOS-made possible in part by supplemental funds from the Bipartisan Budget Act of 2018 and the 2019 Additional Supplemental Appropriations for Disaster Relief Act), the National Science Foundation, and Office of Naval Research. Support for the NOAA and US Navy glider partnership was made possible by NOAA OMAO. Rutgers researchers were also partially supported by NOAA (NA16NOS0120020). This is PMEL contribution \# 5333.

ARTICLE DOI: https://doi.org/10.5670/oceanog.2021.supplement.02-28 


\section{AUTHORS}

Travis N. Miles (tnmiles@marine.rutgers.edu), Sam Coakley, and Scott M. Glenn, Rutgers, The State University of New Jersey, Department of Marine and Coastal Sciences, USA. Dongxiao Zhang, NOAA Pacific Marine Environmental Laboratory, and Cooperative Institute for Climate, Ocean, and Ecosystem Studies, University of Washington, USA. Gregory R. Foltz, Francis Bringas, and Gustavo J. Goni, NOAA Atlantic Oceanographic and Meteorological Laboratory (AOML), USA. Jun A. Zhang, Cooperative Institute for Marine and Atmospheric Studies (CIMAS), University of Miami, USA. Joaquin Triñanes, Department of Electronics and Computer Science, Universidade de Santiago de Compostela, Spain. Christian Meinig and Chidong Zhang, NOAA Pacific Marine Environmental Laboratory, USA. Matthieu Le Hénaff, CIMAS, University of Miami, and NOAA/AOML, USA. Maria F. Aristizabal Vargas, IM Systems Group at NOAA Environmental Modeling Center, USA. Catherine R. Edwards, Skidaway Institute of Oceanography, University of Georgia, USA. Donglai Gong, Virginia Institute of Marine Science, College of William \& Mary, USA. Robert E. Todd, Woods Hole Oceanographic Institution, USA. Matthew J. Oliver, School of Marine Science and Policy, University of Delaware, USA. W. Douglas Wilson, Ocean and Coastal Observing, Virgin Islands. Kerri Whilden and Barbara Kirkpatrick, Gulf of Mexico Coastal Ocean Observing System Regional Association, Texas A\&M University, USA. Patricia Chardon-Maldonado and Julio M. Morell, Caribbean Coastal Ocean Observing System, Puerto Rico. Debra Hernandez, Southeast Coastal Ocean Observing Regional Association, USA. Gerhard Kuska, Mid Atlantic Regional Association Coastal Ocean Observing System, USA. Cheyenne D. Stienbarger, NOAA Global Ocean Monitoring and Observing Program, USA. Kathleen Bailey, NOAA US Integrated Ocean Observing System Office, USA.

\section{ARTICLE CITATION}

Miles, T.N., D. Zhang, G.R. Foltz, J. Zhang, C. Meinig, F. Bringas, J. Triñanes, M. Le Hénaff, M.F. Aristizabal Vargas, S. Coakley, C.R. Edwards, D. Gong, R.E. Todd, M.J. Oliver, W.D. Wilson, K. Whilden, B. Kirkpatrick, P. Chardon-Maldonado, J.M. Morell, D. Hernandez, G. Kuska, C.D. Stienbarger, K. Bailey, C. Zhang, S.M. Glenn, and G.J. Goni. 2021. Uncrewed ocean gliders and saildrones support hurricane forecasting and research. Pp. 78-81 in Frontiers in Ocean Observing: Documenting Ecosystems, Understanding Environmental Changes, Forecasting Hazards. E.S. Kappel, S.K. Juniper, S. Seeyave, E. Smith, and M. Visbeck, eds, A Supplement to Oceanography 34(4), https://doi.org/10.5670/oceanog.2021.supplement.02-28.

\section{COPYRIGHT \& USAGE}

This is an open access article made available under the terms of the Creative Commons Attribution 4.0 International License (https://creativecommons.org/ licenses/by/4.0/), which permits use, sharing, adaptation, distribution, and reproduction in any medium or format as long as users cite the materials appropriately, provide a link to the Creative Commons license, and indicate the changes that were made to the original content. 